\title{
Atribuições e Competências Individuais do Scrum Master: Um Estudo Exploratório
}

\author{
ScrumMaster's Attributions and Competences: An Exploratory Study \\ João Helis J. A. Bernardo \\ Departamento de Informática \\ e Matemática Aplicada \\ Universidade Federal do Rio \\ Grande do Norte (UFRN) \\ Natal/RN - Brasil \\ joaohelis@ppgsc.ufrn.br \\ José Jorge Lima Dias Jr \\ Departamento de Ciências \\ Exatas \\ Universidade Federal da \\ Paraíba (UFPB) \\ Rio Tinto/PB - Brasil \\ jorge@dcx.ufpb.br \\ José Adson O. G. Cunha \\ Centro de Informática \\ Universidade Federal de \\ Pernambuco (UFPE) \\ Recife/PE - Brasil \\ jaogc@cin.ufpe.br
}

\begin{abstract}
RESUMO
A necessidade de entregas rápidas que agreguem o máximo valor de negócio possível ao produto tem ganhado destaque no atual cenário de desenvolvimento de software. No contexto de processos de gerenciamento ágil de projetos baseados no Scrum, um dos papeis essenciais é o do Scrum Master. Torna-se importante, portanto, compreender como este papel está sendo percebido pelos praticantes de desenvolvimento de software, a fim de verificar elementos que estão além do que é proposto no Scrum. Com este intuito, este artigo apresenta um estudo exploratório de natureza qualitativa, realizado para identificar as principais atribuições e competências inerentes ao papel do Scrum Master sob o ponto de vista de profissionais que atuam em equipes de desenvolvimento no setor público. A pesquisa identificou 20 diferentes atribuições do Scrum Master com relação ao Product Owner, ao Time e à organização, e também, 12 competências consideradas importantes para o papel.
\end{abstract}

\section{Palavras-Chave}

Scrum Master, Scrum, Metodologia Ágil, Competências, Atribuições

\begin{abstract}
The need for faster deliveries with maximum business value to the product has gained prominence in current software development scenario. One of the key roles is the ScrumMaster in the context of agile projects management process based on Scrum. In this way, it is important to understand how this role has been perceived by practitioners in software development in order to identify elements that are beyond the proposed by Scrum. Hence, this paper presents a qualitative research, performed to identify attributions and competences inherent to the role of ScrumMaster under professionals
\end{abstract}

Permission to make digital or hard copies of all or part of this work for personal or classroom use is granted without fee provided that copies are not made or distributed for profit or commercial advantage and that copies bear this notice and the full citation on the first page. To copy otherwise, to republish, to post on servers or to redistribute to lists, requires prior specific permission and/or a fee.

SBSI 2016, May 17th-20th, 2016, Florianópolis, Santa Catarina, Brazil Copyright SBC 2016. viewpoint that works in the public sector. This work has identified 20 different ScrumMaster attributions in respect of Product Owner, Team and organization, as also 12 competences considered important to this role.

\section{Categories and Subject Descriptors}

H.1.2 [User/Machine Systems]: Human factors; K.6.3 [Software Management]: Software development

\section{General Terms}

Theory

\section{Keywords}

Scrum Master, Scrum, Agile methodology, Assignments, Skills

\section{INTRODUÇÃO}

Em geral, projetos complexos e altamente inovadores estão inseridos em ambientes de incertezas e grandes desafios, caracterizados pela dificuldade em prever o futuro, onde as técnicas tradicionais de gestão de projetos têm apresentado limitações [19]. Em projetos que envolvem tecnologia, balancear os requisitos do gerenciamento clássico de projetos e as necessidades de uma equipe altamente capacitada e criativa é mais uma arte do que uma ciência [3]. Se por um lado o excesso de formalidade e de processos tende a inibir a equipe e bloquear a inovação, por outro, a falta de estrutura pode fazer com que os objetivos do projeto nunca sejam atingidos.

O Gerenciamento Ágil de Projetos foi criado a partir dos valores e princípios retratados no Manifesto Ágil [8], que valoriza mais indivíduos e interações do que processos e ferramentas, softwares funcionais mais do que a elaboração de documentação, colaboração com o cliente mais do que negociação de contratos, e resposta à mudanças mais do que conformidade aos planos.

O Scrum [17] é a metodologia ágil mais utilizada na indústria para gestão e planejamento de projetos de software [4]. No Scrum, os projetos são divididos em ciclos chamados de sprints, dentro das quais um conjunto de atividades deve ser executado [18]. As funcionalidades a serem implementadas em um projeto são mantidas em uma lista conhecida como Product Backlog. Este método é composto por três papeis 
bem definidos: (i) Scrum Master; (ii) Product Owner; e (iii) Time.

O Scrum Master destaca-se como um papel de fundamental importância dentro do Scrum por, dentre outras atribuições, assegurar a correta execução deste processo. A maneira em que alguns papéis do Scrum são executados e compreendidos podem caracterizar-se como pontos críticos do framework [7], tendo em vista que a má compreensão das atribuições destes papéis influenciam negativamente na aderência e utilização do referido processo, afetando consequentemente a qualidade do produto [20].

Além das habilidades específicas de cada área, o gerenciamento eficaz de projetos exige que o gestor apresente algumas competências, também denominadas de habilidades softs [9], dentre elas, comportamentos a serem desempenhados ao longo do projeto, incluindo atitudes e características de personalidade e liderança. Assim, a forma pela qual o Scrum Master exerce suas atribuições ao longo do processo de desenvolvimento de software impacta o sucesso do projeto de forma positiva ou negativamente.

No âmbito de equipes de desenvolvimento de software do setor público, é visto que aliar a formalidade exigida pelo contexto governamental com a agilidade requerida pelo mercado tem sido um grande desafio [6]. Portanto, as características inerente a este contexto podem influenciar no desenvolvimento dos sistemas de informação.

Alguns trabalhos especificam algumas atribuições inerentes ao papel do Scrum Master [12, 15, 16], entretanto existem poucas pesquisas que levam em consideração as competências e habilidades requeridas ao indivíduo que exerce tal função, principalmente no contexto do setor público. Neste sentido, este trabalho tem o objetivo de apresentar os resultados de uma pesquisa exploratória, qualitativa, sobre as competências e atribuições do Scrum Master, sob o ponto de vista prático dos profissionais que atuam nesta função no setor público.

As demais seções deste trabalho estão estruturadas como segue. A seção 2 apresenta o referencial teórico e os trabalhos relacionados. A seção 3 descreve a metodologia utilizada. A seção 4 apresenta e discute os achados do estudo, fazendo um paralelo com a literatura. A seção 5 elenca algumas limitações da pesquisa. Por fim, a seção 6 apresenta as conclusões e trabalhos futuros.

\section{REFERENCIAL TEÓRICO E TRABALHOS RELACIONADOS}

O Scrum [11] define explicitamente as responsabilidades inerentes a cada um dos papéis que compõe este framework de desenvolvimento ágil. Dentre as atribuições de responsabilidade do Scrum Master, vários trabalhos [2, 12, 15, 16, 17] elencam algumas das mais importantes, a citar, proteger o time de fatores externos que prejudiquem o seu rendimento, eliminar os impedimentos que comprometam o bom andamento do projeto, atualizar e monitorar o gráfico de acompanhamento da evolução do projeto, dentre outras. Além de listar as atividades que são de responsabilidade dos profissionais que exercem a função de Scrum Master, Schwaber [18] explicita a forma com que este papel serve aos demais stakeholders do Scrum.

Poucos estudos focam nos fatores humanos inerentes ao indivíduo que atua como Scrum Master. Dentre os trabalhos encontrados, Cohn [4] lista algumas competências individu- ais ou habilidades humanas requeridas ao profissional que desempenha este papel, tais como, responsabilidade, humildade e comprometimento. De acordo com o autor, o Scrum Master possui autoridade sobre o processo, mas não sobre os demais papeis, o que dificulta o desempenho desta função, se comparado ao de um típico gerente de projetos. Através de uma revisão sistemática da literatura, Querubim [14] apresenta a capacidade de resolução de problemas relacionados ao Time como uma das principais características inerentes ao Scrum Master, que deve ser capaz de tomar decisões direcionadas a eliminar todo e qualquer impedimento que desvirtue o fluxo normal de execução das tarefas do processo.

Diferentemente dos trabalhos supracitados, a presente pesquisa tem o objetivo de apresentar os resultados de uma pesquisa exploratória, qualitativa, sobre as competências e atribuições do Scrum Master, sob o ponto de vista prático dos profissionais que atuam nesta função no setor público. Nesse sentido, a partir da opinião advinda da experiência prática, procura-se identificar e compreender não apenas as principais responsabilidades atribuídas ao Scrum Master, mas também as habilidades humanas inerentes a este papel, tendo em vista um melhor desempenho de suas atribuições.

\section{METODOLOGIA}

A pesquisa é classificada como qualitativa, sob uma postura epistemológica interpretativista. Em tal abordagem existe uma "relação dinâmica entre o mundo real e o sujeito, isto é, um vínculo indissociável entre o mundo objetivo e a subjetividade do sujeito, que não pode ser traduzido em números" [10].

A escolha da abordagem adotada é justificada por entender que as características subjetivas inerentes ao papel do Scrum Master, no que tange as suas atribuições e competências individuais, não podem ser claramente identificadas e compreendidas pela utilização de evidências determinísticas dos fatos, ou seja, por um tratamento quantitativo. O objetivo é identificar o maior número de elementos subjetivos possíveis, a partir da experiência dos praticantes que atuam como Scrum Master no setor público.

\subsection{Coleta de Dados}

O universo desta pesquisa é delimitado pela análise de quatro Scrum Masters que atuam em quatro grandes organizações públicas de desenvolvimento de software de João Pessoa - PB. A seleção dos Scrum Masters escolhidos para realizar a entrevista levou em consideração a experiência destes profissionais com base em dois critérios: (i) tempo em que atua ou atuou como Scrum Master; e (ii) quantidade de projetos em que participou exercendo esta função. Todos os Scrum Masters entrevistados já desempenharam outros papéis dentro do Scrum, seja como membro do Time ou mesmo como Product Owner. Todos os entrevistados da pesquisa atuaram em dois ou mais projetos exercendo o papel de Scrum Master, e tinham mais de dois anos de experiência no exercício dessa função.

A coleta dos dados se deu através de entrevistas semiestruturadas, por fornecer ao entrevistador um entendimento mais detalhado do pensamento dos entrevistados, uma vez que, entrevistas livres, totalmente abertas, são mais propensas a erros de interpretação, pois resultam em um acúmulo de informações, que por vezes, não mostram de forma clara a perspectiva do entrevistado. As entrevistas foram gravadas e posteriormente transcritas. 
A duração média das entrevistas foi de 25 minutos. A Tabela 1 apresenta informações complementares das entrevistas, utilizando tags para substituir os nomes dos entrevistados, afim de garantir a manutenção da confidencialidade.

\subsection{Análise de Dados}

Para a análise dos dados coletados empregou-se o método de análise de conteúdo [1], no qual as etapas de análise são organizadas em três fases: (i) pré-análise; (ii) exploração do material; e (iii) tratamento dos resultados, inferência e interpretação.

A análise do conteúdo das entrevistas foi realizada por meio da Análise Categorial. Em tal abordagem, os textos são agrupados de forma análoga através de categorias, sendo uma boa alternativa quando se busca o estudo e aprofundamento de crenças, valores, opiniões e atitudes. Ou seja, é realizado um agrupamento dos recortes de texto que enquadram-se dentro de um mesmo contexto, para posterior análise.

Este trabalho foi realizado em conformidade com a especificação da proposta de sistematização da aplicação do método de Análise de Conteúdo Temático-Categorial elaborada por Oliveira [13], a qual sugere a aplicação das seguintes etapas:

- Preparação das informações: Considerando que tudo o que pode ser transformado em texto é passível de ser analisado pela técnica de Análise de Conteúdo, todas as entrevistas foram transcritas para serem posteriormente analisadas.

- Transformação do conteúdo em unidades de registro (UR): Nesta etapa, determina-se a escolha do tipo de unidade de registro (palavra, frase ou parágrafo) que será adotada pelo pesquisador no decorrer da análise. Neste trabalho, foi definido como UR os recortes do texto avaliados como relevantes para compreensão do objeto de estudo (Scrum Master). Dessa maneira, realizou-se marcações em todo o texto para cada UR encontrada, conforme exemplificado na Figura 1, onde são elencadas três URs distintas, cada qual pertencente à fala de um Scrum Master.

- Classificação de unidades de registro em temas: Cada unidade de registro é associada a um ou mais temas, com o propósito de associar URs dentro de um mesmo contexto de significação. Cada tema, portanto, é composto por uma ou mais URs, conforme ilustrado na Figura 1, em que as unidades de registro UR01, UR02 e UR03 estão associadas ao tema "ser organizado". Os temas emergem durante o processo de análise, ou seja, não são pré-estabelecidos.

- Classificação de temas em categorias: Refere-se ao agrupamento dos temas e suas respectivas unidades de registro em categorias. Cada categoria está associada a um conjunto de temas, e cada tema à apenas uma categoria. O exemplo ilustrado na Figura 1 apresenta a associação do tema "ser organizado" à categoria "competências do Scrum Master".

- Descrição: Esta etapa corresponde ao resumo numérico das etapas anteriores com o objetivo de apresentar a soma das unidades de registro encontradas no texto de cada entrevista, por tema.
- Interpretação: Esta etapa está relacionada com a pesquisa qualitativa, a qual realiza a análise das evidências encontradas no texto, com base na visão interpretativista. Para cada tema pertencente a uma categoria específica, o investigador deve fazer suas ponderações, a fim de elucidar a compreensão e a importância da existência do tema.

\section{RESULTADOS}

De acordo com a análise desempenhada sobre as entrevistas realizadas com os Scrum Masters, foram identificadas três categorias principais de análise:

\section{(i) Atribuições do Scrum Master;}

(ii) Competências do Scrum Master;

(iii) Falta de Aderência ao Scrum;

Apesar de somente as duas primeiras categorias estarem relacionadas de forma direta com o objetivo inicial do estudo, a categoria "Falta de Aderência ao Scrum" também foi considerada relevante para os resultados deste trabalho, com o propósito de instigar a reflexão das organizações de desenvolvimento de software sobre a importância da correta utilização da estrutura conceitual proposta pelo Scrum, para que assim os benefícios oriundos desta metodologia possam ser obtidos.

Dentro da categoria (i) Atribuições do Scrum Master, emergiram três subcategorias: (i.i) Atribuições do Scrum Master para o Product Owner; (i.ii) Atribuições do Scrum Master para o Time; e (i.iii) Atribuições do Scrum Master para a Organização. Foram identificados um conjunto de temas para cada um dos itens supracitados. A Tabela 2 apresenta detalhadamente as principais atribuições elencadas pelos Scrum Masters entrevistados.

As habilidades humanas potencializam a capacidade do Scrum Master de maximizar o rendimento de todos os envolvidos no framework Scrum. Diante da análise realizada sobre os relatos dos Scrum Masters entrevistados, foram identificados 12 temas referentes a categoria (i) Competências do Scrum Master. Estes temas são apresentados na Tabela 3, que lista as principais competências requeridas ao profissional que trabalha como Scrum Master, sob uma perspectiva prática, ou seja, de acordo com os profissionais que desempenham este papel na indústria de software.

Por fim, identificou-se cinco temas relacionados à categoria de análise (iii) Falta de Aderência ao Scrum. Estes temas refletem medidas que entram em desacordo com a especificação do Scrum, mas que foram observadas dentro dos relatos dos entrevistados.

- O Scrum Master atuando como membro do Time e/ou como Product Owner;

- Não realização das reuniões diárias;

- Falta de aderência as recomendações do Scrum para realização dos eventos;

- Falta de preocupação com a correta utilização do Scrum;

- Não incentivar o autogerenciamento da equipe; 
Tabela 1: Perfil dos entrevistados

\begin{tabular}{|c|c|c|c|c|}
\hline ID & Sexo & Experiência & Quantidade de projetos & Duração da Entrevista \\
\hline \hline SM 01 & $\mathrm{F}$ & 2 anos e três meses & 3 & 24 minutos \\
\hline SM 02 & $\mathrm{M}$ & 5 anos & 4 & 27 minutos \\
\hline SM 03 & $\mathrm{M}$ & 3 anos & 2 & 23 minutos \\
\hline SM 04 & $\mathrm{M}$ & 2 anos & 3 & 28 minutos \\
\hline
\end{tabular}

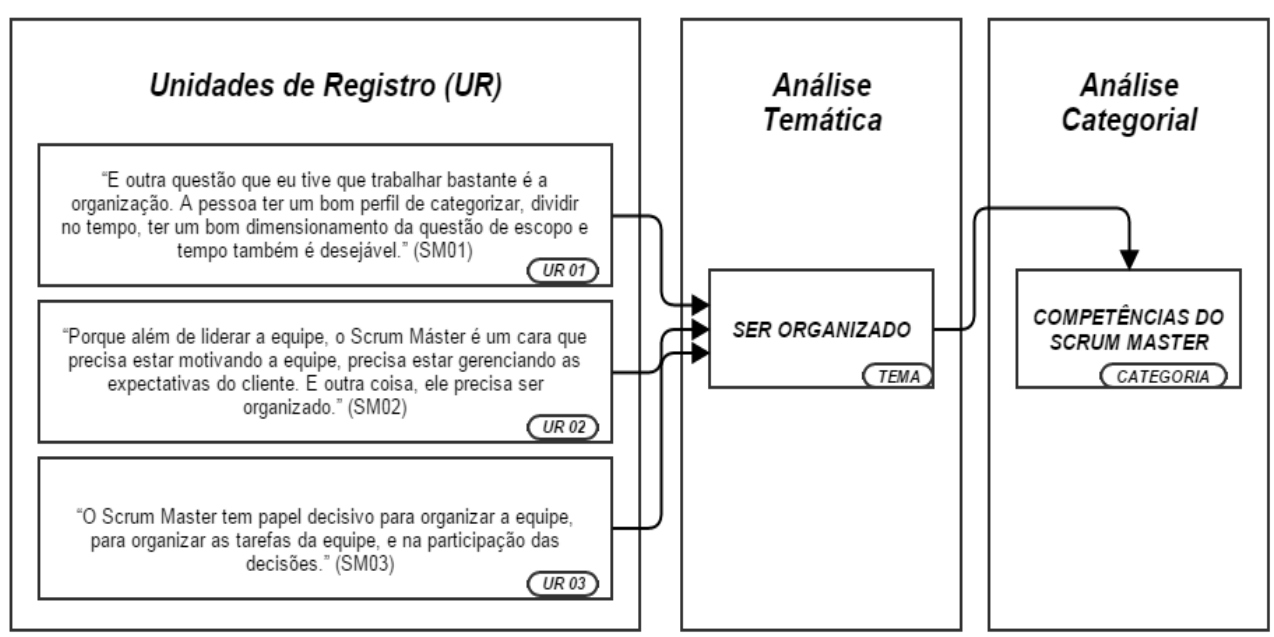

Figura 1: Exemplo de Unidades de Registro (UR), Tema e Categoria

\subsection{Descrição do Resultado}

Esta seção apresenta o resumo numérico da análise categorial do texto oriundo da transcrição literal de todas as entrevistas realizadas, conforme proposto por Oliveira [13], e tem como principal objetivo elencar os temas mais e menos recorrentes dentro dos relatos dos entrevistados.

Dentre todos os temas de cada uma das três categorias de análise que emergiram nesta pesquisa, "ser comunicativo" e "facilitar os eventos do Scrum" apresentaram-se como os de maior recorrência dentre os relatos dos entrevistados, aparecendo em $11,4 \%$ das vezes em que foram identificadas unidades de registro no texto. Dentre os temas menos citados estão "Adaptar o processo a realidade organizacional" e ser "Resiliente".

Na categoria Falta de Aderência ao Scrum, os temas mais recorrentes, cada qual com 3 URs associadas, foram: " $O$ Scrum Master atuando como membro do Time e como Product Owner", "Não realização das reuniões diárias", e "Falta de preocupação com o seguimento do Scrum". O tema menos recorrente, com apenas 1 UR associada, foi "Não incentivar o autogerenciamento da equipe".

É importante ressaltar, portanto, que os temas mais recorrentes dentre os relatos dos entrevistados não necessariamente dizem respeito aos temas mais importantes encontrados na pesquisa, uma vez que, a profundidade pela qual se consegue chegar aos resultados da pesquisa qualitativa vai além da representação numérica de evidências.

As seções 4.2, 4.3 e 4.4 dizem respeito a etapa de interpretação, em que o pesquisador explicita suas análises acerca dos temas elencados no trabalho e justifica a sua importância.

\subsection{Atribuições do Scrum Master}

Com base nos relatos dos entrevistados observou-se que a atividade de acompanhamento do processo de elicitação dos requisitos do projeto junto ao Product Owner é uma das importantes atribuições do Scrum Master, que também tem como responsabilidade direcionar e orientar o $P O$ na tomada de decisões de priorização dos itens do backlog que agreguem o máximo valor sobre o produto desenvolvido.

- "Eu fazia a atividade que começava antes da reunião. Coletar os requisitos e as prioridades com o cliente. A gente elencava alí os requisitos: olhe, esse aqui é prioritário, porque o cliente é quem define. Priorizar e elencar os requisitos, aí preparava a reunião." (SM03)

O Scrum Master interage diretamente com todos os envolvidos no framework Scrum e deve constantemente clarificar as necessidades do cliente junto aos demais stakeholders, com o propósito de gerenciar suas expectativas e promover sua satisfação.

A satisfação do cliente é um dos fatores propulsores da disseminação e utilização do Scrum como uma alternativa ágil de desenvolvimento de software. A quebra de expectativas é um dos elementos que impactam negativamente na satisfação deste importante stakeholder. A proximidade do Product Owner com o projeto facilita constantes feedbacks sobre o que foi desenvolvido, desta forma, é possível validar adequadamente se o produto entregue está em conformidade com o especificado. A comunicação entre estes papeis constitui uma das formas mais diretas e eficientes de gerenciamento de expectativas do cliente.

- "Nunca prometer o que não vai ser entregue, e sempre dar resposta sobre o que está sendo feito. Sempre também pedindo feedback, se o que a gente tá fazendo 
Tabela 2: Atribuições do Scrum Master Atribuições do Scrum Master para o $\mathbf{P O}$

Acompanhar a elicitação dos requisitos do projeto e suas prioridades junto ao $\mathrm{PO}$;

Gerenciar as expectativas e necessidades do Product Owner;

Envolver o Product Owner nas decisões do projeto;

Tornar claro o entendimento sobre os requisitos do projeto com o Product Owner;

Favorecer o estreitamento da relação entre o Product Owner e o projeto;

Atribuições do Scrum Master para o Time

Entender os percalços dos membros do Time;

Compartilhar a responsabilidade do projeto com o Time; Favorecer a construção de um Time interdisciplinar e autogerenciável;

Gerenciar as expectativas do Time;

Identificar fatores motivacionais para a equipe e motivála;

Remover impedimentos do Time;

Atribuições do Scrum Master para a Organização

Facilitar e acompanhar o andamento do processo;

Facilitar o entendimento comum sobre os aspectos do Scrum;

Facilitar os eventos do Scrum;

Proporcionar a aderência ao processo;

Facilitar um ambiente harmonioso;

Gerenciar conflitos internos e externos;

Identificar pontos de melhoria do processo;

Promover transparência sobre o andamento do projeto;

Adaptar o processo a realidade organizacional;

tá de acordo com a expectativa, se a gente tá desenvolvendo o que ele realmente tá querendo. Sempre manter a comunicação com ele para gerenciar as expectativas. Porque além de liderar a equipe, o Scrum Máster é um cara que precisa estar motivando a equipe, precisa estar gerenciando as expectativas do cliente." (SM02).

Todos os entrevistados elencaram também como atribuição do Scrum Master a atividade de remover os possíveis impedimentos do Time, caracterizando esta tarefa como de suma importância para a evolução do projeto.

- "Para a equipe de desenvolvimento em si, eu permeio sempre naquela coisa de tirar os possíveis impedimentos. Facilitar a equipe, caso haja algum impedimento no andamento do projeto, então, eu preciso comunicar novamente." (SM01).

- "Estou sempre me comunicando, na verdade. Perguntando se existe algum conflito, e perguntando a ele o Status de uma tarefa, se vai ser entregue no prazo, se ele tá com alguma dificuldade, se está precisando de alguma coisa que não dependa dele. Se tem alguma coisa impedindo que ele continue." (SM02)

O Scrum é um framework dentro do qual é possível empregar vários processos e técnicas, onde "as pessoas podem tratar e resolver problemas complexos e adaptativos, enquanto produtiva e criativamente entregam produtos com o mais alto valor possível" [18]. O Scrum Master deve ser capaz de realizar as adaptações cabíveis do processo, de acordo com a realidade organizacional.

- "O Scrum prega que a reunião diária tem que ser feita
Tabela 3: Competências do Scrum Master Competências do Scrum Master

Sociabilidade;

Capacidade de ouvir os interessados do projeto;

Saber planejar;

Comunicativo;

Disciplinado;

Humilde;

Justo;

Resiliente;

Organizado;

Liderança;

Poder de negociação e convencimento;

Capacidade de oratória;

em pé, de frente ao quadro. A gente não usou quadro em todos os projetos. Alguns projetos utilizavam, outros não. Mas a gente fazia coisas que substituíam, por exemplo, no redmine a gente tinha um quadro alí, porque quando a gente criava as Sprints, a gente criava dentro das Sprints as histórias, e dentro das histórias as tarefas. Então se a gente clicasse na Sprint a gente tinha um quadro, porque a gente via o que estava em andamento, o que está revisando, o que tem pra fazer. Mas nós adaptávamos o processo para a realidade da gente" (SM02).

$\mathrm{O}$ entendimento do estado atual do projeto e das metas pretendidas deve ser transparente para todos os stakeholders envolvidos no processo de desenvolvimento de software, como forma de gerenciar as expectativas. O Scrum Master deve prover os instrumentos necessários para realização do acompanhamento do projeto, assim como, oferecer subsídios necessários para que se possa validar de forma tangível o cumprimento das metas estabelecidas.

- "Ele deve compartilhar tudo com a equipe, para que todos se sintam responsável pelo projeto, pelo seu sucesso ou pelo seu fracasso, mas claro, como ele está à frente ele tem que assumir algumas responsabilidades a mais, de forma geral, isso deve ser compartilhado com a equipe da forma mais transparente possivel." (SM04).

- "Então assim, a postura foi sempre de transparência e de compartilhamento dos problemas no sentido de deixar todos cientes do que estava acontecendo, e as reuniões diárias eram muito importantes, porque era a oportunidade em que todos falavam sobre o que estava acontecendo de errado, e ao mesmo tempo todos tentavam se ajudar propondo soluções para tudo aquilo que era levantado como problema. (SM04).

A harmonia entre as partes envolvidas no projeto apresentáse como uma característica imprescindível para a organização, uma vez que, um ambiente harmonioso, onde pessoas podem interagir naturalmente uma com as outras, pautando suas ações na preservação da boa relação intersocial do grupo, é visto como um fator que influencia positivamente na produtividade da equipe como um todo.

- "O Scrum Master é o mediador, para deixar a equipe trabalhar tranquilamente. Então, eu acho que essa daí é a principal característica do Scrum Master." (SM03).

- "Mas assim, de forma geral ele tem que facilitar, fazer com que os outros trabalhem. O papel do Scrum Master é fornecer todos os insumos necessário para que 
a equipe trabalhe, e garantir que exista um ambiente harmonioso" (SM04).

De acordo com alguns autores da literatura [18, 17] a atividade de facilitar os eventos do Scrum constitui uma das principais atribuições inerentes ao papel do Scrum Master. Foi verificado que facilitar as reuniões previstas pelo Scrum é uma das atribuições onde o Scrum Master tem papel fundamental. Ele deve cobrar a realização destes eventos, garantindo o correto funcionamento do processo. Cada um dos eventos do Scrum tem função primordial dentro do framework, uma vez que, objetivam-se também em efetuar a inspeção e adaptação do produto e do processo.

- "De forma geral o Scrum Master tem que necessariamente estar no planejamento do tamanho, escopo e prazo dos produtos entregáveis. A questão da aceitação de requisitos. O mapeamento das regras de negócio, anterior a isso, para chegar a aceitação. A gente faz uma retrospectiva da Sprint junto com a equipe, pra poder até dimensionar o próximo planejamento." (SM01).

- "O que eu procurava fazer como Scrum Master para garantir isso, era lembrar de fazer a reunião diária. Era ao final do projeto fazer a review, fazer a retrospectiva, fazer o planejamento, selecionar as estórias junto com o cliente." (SM02).

- "Chamando, motivando o pessoal para que siga todo o processo definido pelo Scrum. Convocando o pessoal para reunião diária, para fazer o planejamento, mensurar as tarefas, dividir as tarefas, selecionar as histórias junto com o cliente." (SM02).

\subsection{Competências do Scrum Master}

De acordo com os relatos extraídos das entrevistas realizadas, o Scrum Master deve ser capaz de manter-se atento nas necessidades do Time e do $P O$, utilizando apropriadamente a competência de ouvir estes papeis, com o objetivo de gerenciar as expectativas dos stakeholders e facilitar o andamento do processo.

- "Na minha opinião, a responsabilidade do Scrum Master é escutar a equipe, porque na reunião diária ele tem que escutar a equipe para saber o que é que a equipe está precisando, saber o que ela está passando, o que é que ela tá fazendo. Então a gente tem que estar alí sempre escutando e conversando com a equipe." (SM03)

A comunicação tem papel fundamental dentro de um grupo, sendo corroborada pelas falas dos entrevistados. Líderes que se comunicam bem com os seus liderados instigam com facilidade a contribuição destes para com o projeto. Nesse contexto, é relevante destacar a importância da comunicação como uma ferramenta estratégica indispensável para o exercício da liderança.

- "Tem mais a ver com a questão de comunicar, deixar todo mundo informado com a questão de projeto, andamento e tudo, e facilitar. Então, é mais comunicador e facilitador do andamento do projeto. Principalmente comunicar, porque na produção em si, o Scrum Master planeja, mas em geral os requisitos já vieram construídos de um mapeamento anterior, não necessariamente pelo Scrum Master. (SM01)

- "Então é mais essa questão de comunicação. O Scrum Master deve estar sempre se comunicando. Ele tem que estar sempre se comunicando com a equipe para evitar que alguns conflitos impeçam o andamento de um projeto, a evolução. Ele precisa ser um bom comunica- dor." (SM02)

Os relatos dos entrevistados evidenciam a liderança como uma competência de suma importância. O Scrum Master, líder da equipe, deve ter algumas características que o ajudem a liderar o Time de desenvolvimento eficientemente, como: ter espírito de equipe, ter autoconhecimento, versatilidade e bom relacionamento.

- "Bem, para mim ser Scrum Master é liderar, é você estar à frente e sempre saber o que está se passando com a equipe de bom ou de ruim, é ajudar eles a resolverem os problemas. Ele tem que exercer esse papel de liderança, tem que estar a frente e defender a equipe, porque sempre aparecem empecilhos no meio do projeto. Então, "- Olhe, aqui não dá"'. (SM03)

- "Ele tem que ter as habilidades de comunicação, liderança, motivação, capaz de gerenciar conflitos, e assim por diante. Eu acho que através dessas características ele pode influenciar positivamente na qualidade do software, garantindo um ambiente harmonioso junto a equipe." (SM04)

Dentre as competências desejáveis a um bom Scrum Master, o entrevistado SM01 cita a boa oratória, a qual está relacionada com a capacidade de persuasão de um indivíduo. A forma pela qual o Scrum Master direciona suas ideias ao Time de desenvolvimento e também ao Product Owner pode constituir diferentes julgamentos de quão boa são ou não tais ideias. Assim, é importante que o líder seja capaz de falar da forma mais natural possível com seus liderados, e com todas as pessoas com as quais mantém relação, com o propósito de apresentar de forma ética e coesa o seu ponto de vista, sem que haja maiores impedimentos ou distorções de ideias.

- "Eu acho que essa questão da oratória. Porque quando está só a equipe pequenininha, a gente conversa de boa. Mas se passar para o dia da apresentação da Sprint, se tiver mais gente alí, eu não me sinto muito bem." (SM03)

Um dos principais desafios do Scrum Master no que se refere ao relacionamento e sociabilidade no ambiente de trabalho é de promover a boa convivência com todos os stakeholders envolvidos no Scrum, entendendo que as pessoas possuem comportamento, visão e cultura diferentes, e desta forma, respeitando tais diferenças. A habilidade de sociabilidade é constatada como imprescindível ao Scrum Master, e deve basear-se em cinco pilares: autoconhecimento, empatia, assertividade, cordialidade e ética.

Identificamos a partir dos relatos dos entrevistados a competência de saber planejar como uma das competências de suma importância para o bom desempenho do papel de Scrum Master. O planejamento apresentá-se como uma atividade imprescindível em um ambiente onde os recursos são escassos. Os recursos podem ser vistos como: tempo, pessoas, máquinas, e assim por diante. Desta maneira, o gerenciamento adequado da utilização destes recursos apresentáse como um fator determinante na produtividade de uma equipe. Saber estimar o tempo necessário para a realização de uma tarefa e planejar adequadamente o esforço necessário da equipe para o cumprimento das suas metas são exemplos de atividades de planejamento que devem estar no escopo de domínio do Scrum Master.

- "A lidar com resoluções de conflitos. Conseguir planejar melhor, ter a ideia da importância do planejamento. Liderar a equipe." (SM02) 
- "Outra questão de habilidade que não é de pessoa, mas requer também uma certa atenção, é a melhoria da questão de cálculos de custos. Como aqui a gente não tem um custo monetário, claro, setor público tem esse problema. Então, a questão de custo de tempo, de recursos, não tenho essa habilidade também de calcular um ponto de função. Já li muito sobre a questão, mas eu não utilizo. Então, vamos dizer assim, essas boas práticas talvez eu esteja precisando melhor me situar. (SM01)".

\subsection{Falta de Aderência ao Scrum}

O Scrum propõe que cada papel tenha suas próprias atribuições, e que tais atribuições não se sobreponham, por exemplo, o Scrum Master não deve realizar tarefas de responsabilidade do Time. Com base nos relatos dos entrevistados, percebeu-se que essa recomendação não estava sendo seguida.

- "Se preciso eu vou desenvolver junto, se precisar eu vou fazer um ré-análise, se precisar vou dar uma força na equipe de teste. Ao máximo, você tenta não ficar presa nas atividades em si, mas facilitando para que elas desemperrem." (SM01)

- "Só para resgatar um pouco. Quando eu fui Scrum Master eu também sempre realizei tarefas. Eu não fazia só o papel de Scrum Master, porque como a equipe não era muito grande, além de fazer o papel do Scrum Master em si, eu também pegava tarefas para executar." (SM02)

Todos os eventos prescritos no Scrum são essenciais para que o objetivo do processo seja alcançado, entretanto, os relatos apontam que alguns Scrum Masters entrevistados não seguem ou realizam tais eventos. Os eventos do framework Scrum são compostos por: reunião diária, reunião de planejamento da Sprint, reunião de revisão da Sprint, e reunião de retrospectiva da Sprint. Cada um destes eventos tem um objetivo singular dentro da dinâmica do processo, que compreende desde acompanhar o andamento do projeto até identificar e aplicar pontos de melhoria do processo. A reunião diária, por sua vez, tem a finalidade de fazer com que os membros da equipe possam coletivamente inspecionar o seu progresso em direção à meta da Sprint.

- "Não fazemos reuniões diárias, mas fazemos reuniões presenciais pelo menos uma vez por semana." (SM01)

- "Na verdade a gente tentava usar o Scrum o máximo possivel, mas nunca era possivel usar todo o Scrum. Então tinha prática que nós sabíamos que era uma boa prática, mas no dia-a-dia, na dinâmica do projeto a gente deixava de utilizar, como as reuniões diárias. Porque a equipe era pequena e conversava muito, então a gente não precisava fazer reuniões diárias." (SM03)

De acordo com Schwaber e Sutherland [18], uma das atribuições do Scrum Master refere-se ao treinamento do time de desenvolvimento em autogerenciamento e interdisciplinaridade. O Time deve se auto-organizar e coletivamente planejar e gerenciar a forma pela qual suas atribuições devem ser executadas. No entanto, foram constatadas inconsistências neste aspecto, conforme indicado na fala do entrevistado SM04, na qual foi possível perceber uma característica de centralização das decisões da equipe pelo Scrum Master, o que desvirtua a característica de autogerenciamento do Time pregada pelo Scrum.

- "Então eu me cobrava muito em participar de tudo, pelo menos na teoria não deve ser bem assim, a gente tem que deixar a equipe trabalhar por conta própria e ela tentar resolver os problemas. Só que eu me cobrava muito por conta disso né, por receber uma gratificação muito grande, eu me sentia na obrigação de ser do caminho crítico de todo tipo de coisa que acontecesse no projeto." (SM04)

\subsection{Atribuições e Competências do Scrum Mas- ter na teoria e prática}

Esta seção faz um paralelo entre teoria e prática, no que diz respeito as atribuições e competências inerentes ao papel do Scrum Master. É realizada uma análise comparativa entre os resultados desta pesquisa e as atribuições e competências do Scrum Master já assinaladas na literatura. Busca-se confrontar as informações de forma analítica, afim de verificar os pontos em que a prática constatou as afirmações teóricas, e além disso, elencar pontos que apareceram na análise realizada nesta pesquisa, mas que ainda não haviam sido mencionados na literatura.

O Scrum Guide [18] define como o Scrum deve ser utilizado para o desenvolvimento de projetos. Este trabalho elenca também as principais atividades inerentes a cada papel que integra o framework Scrum. No que diz respeito ao Scrum Master, Schwaber at al. [18] elenca algumas atribuições para este papel, e estas estão direcionadas a servir o Product Owner, o Time, e a organização. Seis das atribuições definidas no Scrum Guide [18] foram também constatadas dentre os relatos dos entrevistados desta pesquisa. Foram elas:

- Compartilhar a responsabilidade do projeto com o Time;

- Favorecer a construção de um Time interdisciplinar e autogerenciável;

- Remover impedimentos do Time;

- Facilitar os eventos do Scrum;

- Proporcionar a aderência ao processo;

- Identificar pontos de melhoria do processo;

Com base no melhor do conhecimento dos autores, as quatorze demais atribuições elencadas no presente artigo (Tabela 2) não foram previamente citadas na literatura, entretanto, são assinaladas como de grande importância para o profissional que exerce o papel de Scrum Master, de acordo com a opinião dos profissionais que exercem esta função dentro da indústria de software.

No que diz respeito as competências inerentes ao papel do Scrum Master, Querubim [14] identifica algumas das mais importantes, a partir de uma revisão sistemática da literatura. Dentre as competências identificadas na literatura, cinco foram também observadas a partir dos relatos dos entrevistados desta pesquisa. Foram elas:

- Comunicativo

- Disciplinado;

- Humilde;

- Liderança;

- Capacidade de oratória; 
As sete demais competências assinaladas nesta pesquisa podem ser visualizadas a partir da Tabela 3, que mostra outras importantes habilidades requeridas ao profissional que exerce o papel de Scrum Master.

Observou-se, portanto, que algumas das atribuições e competências elencadas na literatura foram também retratadas nos relatos dos profissionais que atuam como Scrum Master no setor público, o que valida a importância dessas características para quem exerce este papel. A presente pesquisa elencou 20 atribuições e 12 competências inerentes ao papel do Scrum Master, analisadas sob uma perspectiva prática. Muitas características observadas nos resultados deste estudo ainda não tinham sido retratadas na literatura, de tal forma, configura-se relevante tanto para a academia quanto para o contexto do setor público, pois permite compreender melhor o papel do Scrum Master na prática, e por conseguinte, utilizar apropriadamente o Scrum para gerenciar projetos inseridos em ambientes reais de desenvolvimento.

\section{LIMITAÇÕES DO ESTUDO}

Uma ameaça aos resultados está relacionada à experiência dos entrevistados, tendo em vista que foram investigados Scrum Masters com experiência relativamente baixa, um com dois e outro com dois anos e três meses de experiência exercendo esta função. Embora o processo de análise tenha conseguido extrair significativas informações a partir dos relatos oriundos das entrevistas realizadas, uma maior quantidade de indivíduos poderia ter sido pesquisada com o propósito de atingir a saturação dos dados, inerente a uma pesquisa qualitativa, e assegurar a validade de conclusão dos resultados.

Diferentemente do paradigma pós-positivista que busca generalizar os seus resultados [5], a abordagem interpretativista, materializada aqui através da pesquisa qualitativa, objetiva entender cada estudo em seu contexto específico, com o propósito de adquirir os conhecimentos oriundos do ambiente em que o estudo foi aplicado, não necessariamente com o objetivo de generalizá-los.

\section{CONCLUSÃO E TRABALHOS FUTUROS}

Uma lista de atribuições referentes ao papel do Scrum Master foi elencada através de uma abordagem qualitativa, baseada na experiência prática dos entrevistados da pesquisa. Foi possível verificar a partir deste estudo a existência e a importância de um conjunto de competências individuais requeridas ao indivíduo que atua neste papel, tais como: boa comunicação e organização, por exemplo. Foi identificado também a falta de aderência com algumas recomendações prescritas pelo framework Scrum, emergindo a categoria de análise "Falta de Aderência ao Scrum".

Este estudo contribui para uma melhor capacitação de Scrum Masters, uma vez que possibilita o entendimento das principais atribuições e competências inerentes a este papel sob uma perspectiva prática, analisando-as sob o ponto de vista de praticantes do setor público.

Como trabalho futuro, sugere-se reaplicar o método de entrevista com outros Scrum Masters, a fim de explorar mais o contexto do setor público; realizar um survey com Scrum Masters e membros da indústria de software para validação dos resultados do estudo; e por fim, realizar a mesma pesquisa para análise das atribuições e competências inerentes aos demais papeis do Scrum.

\section{REFERÊNCIAS}

[1] L. Bardin. Content analysis. Editions Lisbon, 1977.

[2] J. M. Bass. Scrum master activities: Process tailoring in large enterprise projects. In Global Software Engineering (ICGSE), 2014 IEEE 9th International Conference on, pages 6-15. IEEE, 2014.

[3] G. Chin. Agile project management: how to succeed in the face of changing project requirements. AMACOM Div American Mgmt Assn, 2004.

[4] M. Cohn. Succeeding with agile: software development using Scrum. Pearson Education, 2010.

[5] J. W. Creswell. Research design: Qualitative, quantitative, and mixed methods approaches. Sage publications, 2013.

[6] A. Cunha. Gerenciamento Ágil de projetos de software em uma empresa pública de ti: Um estudo de caso. $V$ Workshop de Gerenciamento de Projetos de Software, 2011.

[7] J. J. L. Dias Jr, A. F. P. Belo, and F. N. Dias. Percepções sobre um processo de software sob o ponto de vista das equipes de desenvolvimento: Um estudo de caso. $S B Q S, 2014$.

[8] M. Fowler and J. Highsmith. The agile manifesto. Software Development, 9(8):28-35, 2001.

[9] S. Gillard. Soft skills and technical expertise of effective project managers. Issues in Informing Science and Information Technology, 6(7), 2009.

[10] F. d. S. KAUARK, F. C. Manhães, and C. H. Medeiros. Metodologia da pesquisa: um guia prático. Bahia: Via Litterarum, 2010.

[11] H. Kniberg. Scrum and XP from the Trenches: Enterprise Software Development. Lulu.com, 2007.

[12] A. Mundra, S. Misra, and C. A. Dhawale. Practical scrum-scrum team: Way to produce successful and quality software. In Computational Science and Its Applications (ICCSA).

[13] D. C. d. Oliveira. Análise de conteúdo temático-categorial: uma proposta de sistematização. Rev. enferm. UERJ, 16(4):569-576, 2008.

[14] T. d. S. Querubim. Proposta de um conjunto de competências para um scrum master. Monografia (Bacharelado em Eng. de Software)-UnB, 2015.

[15] K. S. Rubin. Essential Scrum: A practical guide to the most popular Agile process. Addison-Wesley, 2012.

[16] K. Schwaber. Agile project management with Scrum. Microsoft press, 2004.

[17] K. Schwaber and J. Sutherland. The scrum guide. Scrum Alliance, 2011.

[18] K. Schwaber, J. Sutherland, and M. Beedle. The definitive guide to scrum: The rules of the game. 2013.

[19] R. Suikki, R. Tromstedt, and H. Haapasalo. Project management competence development framework in turbulent business environment. Technovation, 26(5):723-738, 2006.

[20] A. N. Tsukumo, C. M. Rêgo, C. F. Salviano, G. F. Azevedo, L. K. Meneghetti, M. C. Costa, M. B. d. CARVALHO, and R. M. Colombo. Qualidade de software: visões de produto e processo de software. CITS, 1997. 